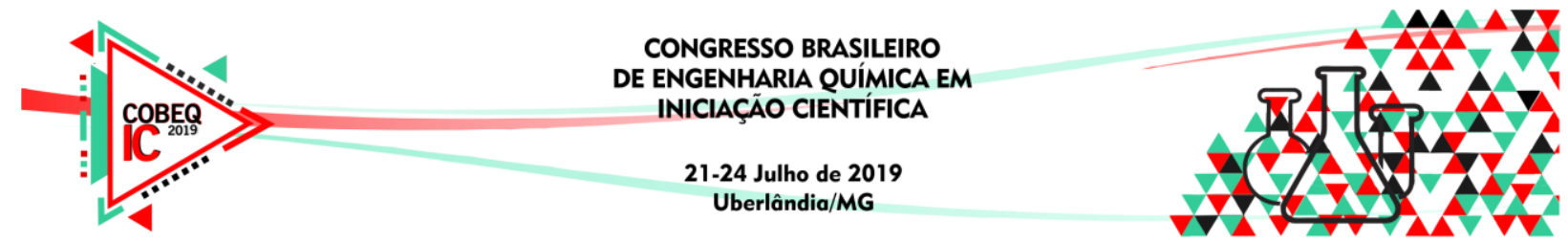

\title{
EFEITOS DO USO DE SECADOR ROTATÓRIO COM RECHEIO DE INERTES NOS COMPOSTOS BIOATIVOS DO CAMU-CAMU (Myrciaria dubia)
}

\author{
T. C. FONSECA ${ }^{1}$, T. C. SILVA ${ }^{1}$, N. C. SILVA ${ }^{1}$, C. R. DUARTE ${ }^{1}$ e M. A. S. BARROZO ${ }^{1}$ \\ ${ }^{1}$ Universidade Federal de Uberlândia, Faculdade de Engenharia Química \\ E-mail para contato: thabata.carmo.fonseca@hotmail.com
}

\begin{abstract}
RESUMO - O camu-camu (Myrciaria dubia) é um fruto tropical nativo da região Amazônica, que têm despertado interesse pelo seu elevado conteúdo de compostos bioativos, como a vitamina $\mathrm{C}$ e antioxidantes Porém, esse fruto apresenta alto teor de umidade, sendo necessária a aplicação de técnicas de desidratação. Dentre as técnicas existentes, o secador rotatório com recheio de inertes tem tido grande relevância uma vez que o equipamento se destaca pela possibilidade de secar materiais pastosos e por gerar um produto pós-secagem pronto para comercialização. Para definição da melhor condição experimental de secagem da polpa, almejando-se a obtenção de um produto com altos teores de compostos bioativos (fenólicos totais, flavonóides, ácido cítrico e ácido ascórbico), foram explorados os efeitos de diferentes concentrações do agente carreador (maltodextrina), da temperatura do ar, do fator de enchimento e da velocidade de rotação durante o processo. Os resultados obtidos indicaram que o método causou certo impacto nos teores tendo seus valores mantidos próximos ou abaixo dos da polpa in natura sob condições específicas e que a utilização de maltodextrina foi positiva no processo por atuar como um "protetor térmico".
\end{abstract}

\section{INTRODUÇÃO}

O camu-camu é um fruto originário da região amazônica que tem se destacado por despertar o interesse de indústrias farmacêuticas internacionais devido seus elevados teores de antioxidantes, em especial a vitamina C. Contudo, essa alta concentração de compostos antioxidantes acarreta um sabor ácido à fruta inibindo o consumo in natura (Rodrigues et al., 2004). Juntamente a essa acidez característica, a polpa de camu-camu também tem elevada quantidade de água, que torna o fruto altamente perecível (Fujita et al., 2013). Nesse sentido faz-se necessário um método para conservação do material

Dentre as variadas técnicas de desidratação, o secador rotatório tem se destacado por possuir como vantagens a alta eficiência na remoção da umidade e promoção de uma secagem mais homogênea devido ao seu alto grau de mistura de partículas (Krokida et al., 2002). Como a biomassa do camu-camu é pastosa, o uso de inertes dentro do secador rotatório se torna bastante efetivo, uma vez que os mesmos maximizam a troca térmica e evitam perdas do material nas paredes e outras estruturas do secador (Freitas, 2017). 


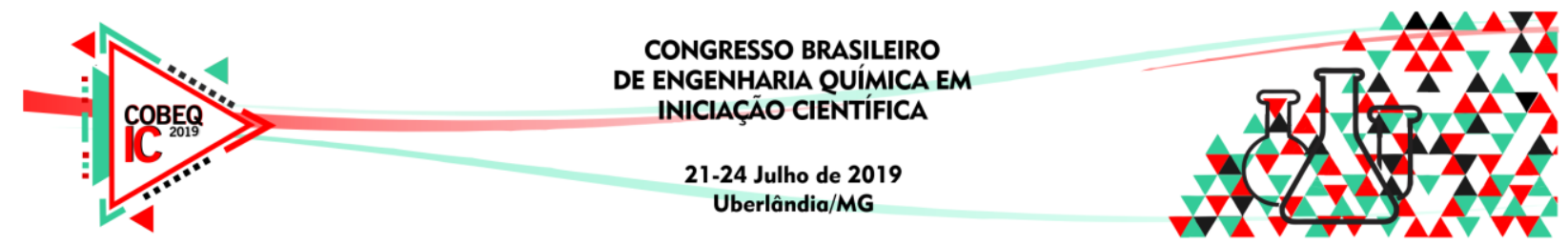

Diante de todos estes fatos, o objetivo deste trabalho foi realizar a desidratação do camu-camu utilizando um secador rotatório com recheio de inertes, analisando o impacto da variação das condições de operação sobre os teores de compostos bioativos presentes no fruto.

\section{MATERIAL E MÉTODOS}

O camu-camu utilizado foi fornecido por um sítio localizado em Ibiá-MG. Foi preparada a polpa dos frutos, adicionando-se água destilada na proporção mássica 3:4 (3 g de água para cada $4 \mathrm{~g}$ de fruto). A polpa foi armazenada em copos plásticos, envoltos em polietileno e papel alumínio, sendo mantidos em freezer à $-18^{\circ} \mathrm{C}$, até o momento da realização dos experimentos.

A unidade experimental utilizada, representada na Figura 1, consistia em um soprador, conectado a um sistema de aquecimento e um variador de voltagem para ajustar a temperatura do ar. O tambor foi conectado a um sistema de rotação composto por um motor e inversor de frequência para controle da velocidade de rotação. Um ciclone Stairmand de diâmetro $10 \mathrm{~cm}$ e com um frasco acoplado em seu underflow foi utilizado para coleta do material desidratado. $\mathrm{O}$ camu-camu in natura foi alimentado por um sistema composto por um tanque de armazenamento, bomba peristáltica e controlador de velocidade. O tambor usado neste trabalho foi feito de aço inox, com diâmetro interno de $12 \mathrm{~cm}$ e comprimento de $36 \mathrm{~cm}$. Os inertes utilizados foram esferas de porcelana, com diâmetro de 1,9 cm e densidade de 2,32 $\mathrm{g} / \mathrm{cm}^{3}$.

Figura 1- Figura esquemática do secador rotatório com recheio de inertes.

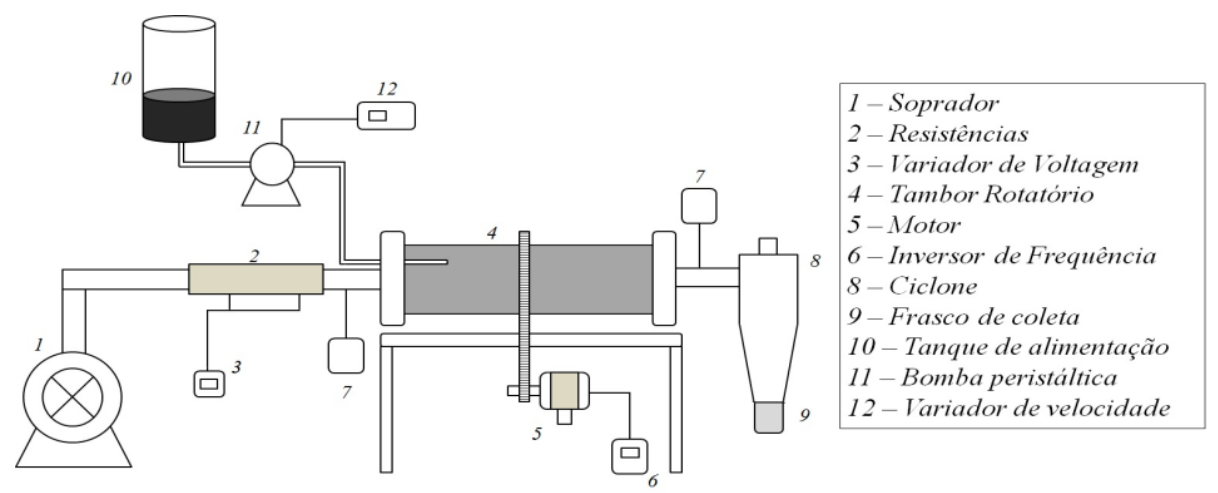

Utilizou-se cerca de $100 \mathrm{~g}$ de polpa de camu-camu em cada experimento, alimentadas na forma de ciclos intermitentes. Analisou-se os impactos das variáveis temperatura do ar, enchimento e rotação no processo de secagem. Além dessas variáveis, verificou-se os efeitos de diferentes concentrações de maltodextrina na polpa durante a secagem, realizando-se uma série de experimentos em concentrações distintas desse agente carreador. Para tal, após descongelada, a polpa era misturada com a maltodextrina (Loremalt, DE11). A concentração era calculada da seguinte forma: para 10\% de maltodextrina, adicionava-se $10 \mathrm{~g}$ do agente carreador à $100 \mathrm{~g}$ de polpa, e assim, para as demais concentrações avaliadas.

Foram realizados 11 experimentos, onde primeiramente buscou manter as variáveis constantes, analisando apenas o efeito da variação da concentração de maltodextrina no 


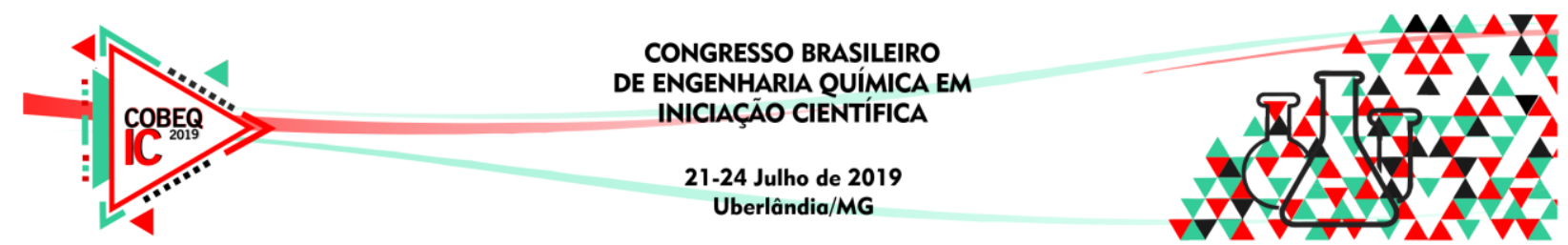

processo, dentre as concentrações de $0,10,15,20$ e 30\%. Com a melhor concentração de maltodextrina definida, variou-se então a temperatura, entre 70,90 e $110^{\circ} \mathrm{C}$ mantendo as demais variáveis constantes. Posteriormente avaliou-se o efeito do grau de enchimento do tambor rotatório, entre 21,28 e $35 \%$, mantendo novamente as outras variáveis constantes. Por fim, alternou-se a rotação do tambor rotatório, entre os valores de 55, 65 e 75 RPM.

Quanto as análises realizadas, no material in natura e após a desidratação, o Teor de Fenólicos Totais (TPC) foi determinado pelo Método de Folin Ciocalteau (Singleton e Rossi, 1965), usando ácido gálico como padrão de referência e leitura no espectrofotômetro à 622 $\mathrm{nm}$. Os resultados foram expressos em $\mathrm{mg}$ ácido gálico/100 $\mathrm{g}$ de amostra em base seca; o Teor de Flavonóides Totais (TFC) foi determinado pelo método colorimétrico descrito por Zhishen et al. (1999), utilizando leitura em espectrofotômetro à $450 \mathrm{~nm}$ e a rutina como padrão. Os resultados foram expressos em $\mathrm{mg}$ de rutina/100 $\mathrm{g}$ de amostra em base seca; o Teor de Acidez (TA) foi determinado pela titulação das amostras com $\mathrm{NaOH}$ padronizado, e expressa em mg de ácido cítrico/100 g da amostra em base seca (AOAC, 1995); e o Teor de Ácido Ascórbico (AA) que foi determinado pela análise em que ácido oxálico $2 \%$ é adicionado aos extratos obtidos na maceração e a solução resultante foi titulada com solução de 2,6diclorofenol-indofenol (DCFI) 0,025\% padronizado. Os resultados foram expressos em $\mathrm{mg}$ de ácido ascórbico/ $100 \mathrm{~g}$ amostra em base seca (AOAC, 1995).

\section{RESULTADOS E DISCUSSÃO}

O efeito das diferentes concentrações de maltodextrina nos teores dos compostos bioativos é apresentado na Figura 2 a seguir.

Figura 2- Teores de compostos bioativos após a desidratação de camu-camu- Efeito da maltodextrina: (a) TPC; (b) TFC; (c) ATT e (d) AA.
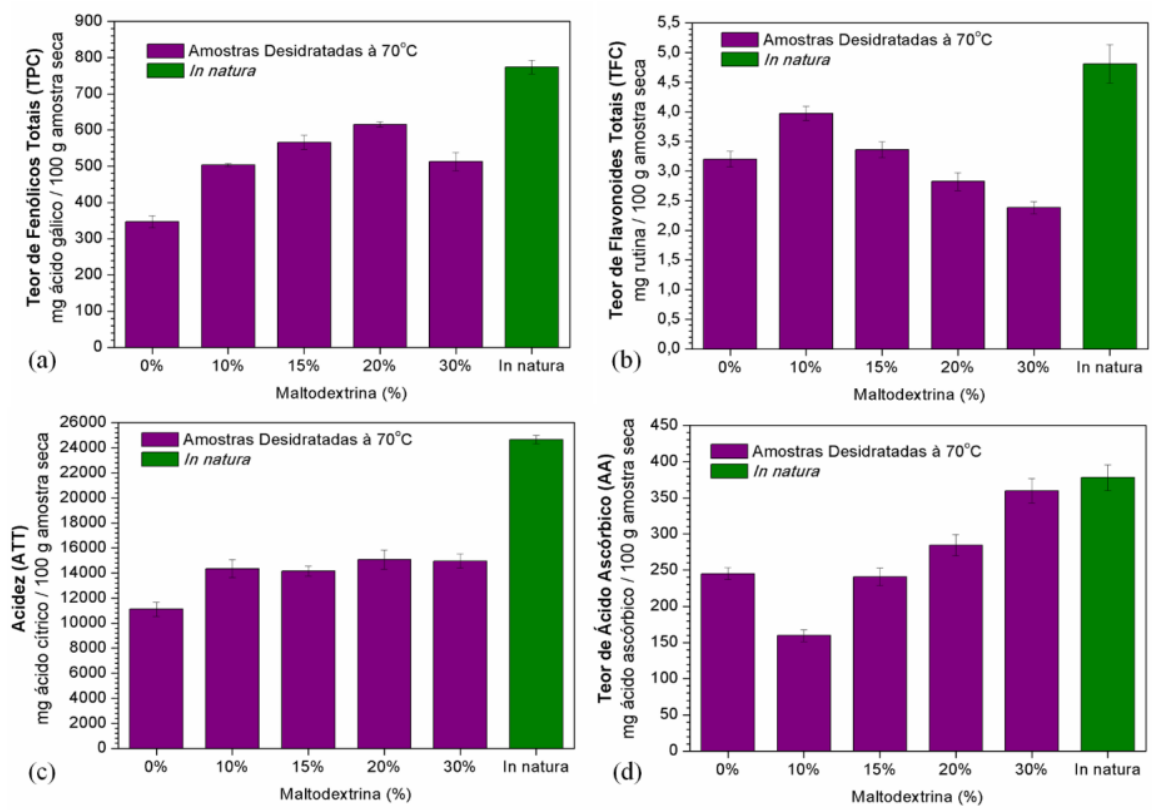

O Teor de Fenólicos Totais (Figura 2a) obtido nos experimentos indicou que o teor desses compostos aumentou gradualmente e consideravelmente em relação às amostras sem 


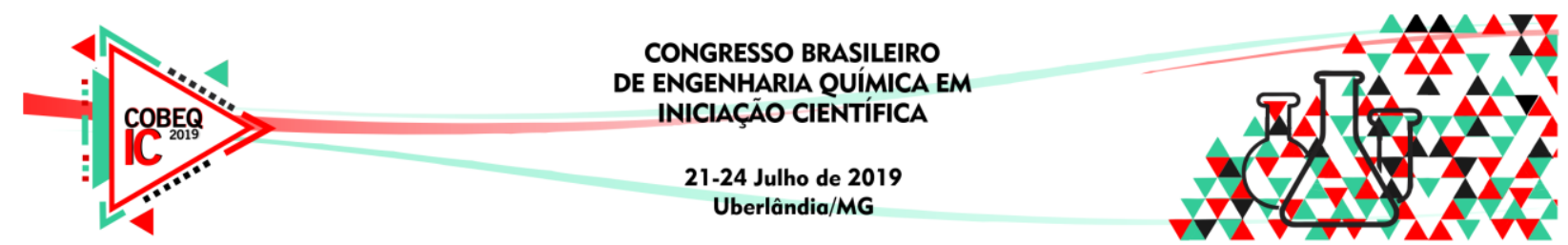

maltodextrina até atingir a faixa dos $20 \%$ de concentração, onde o TPC obtido foi de 615,33 mg ácido gálico/100 g amostra. Ramírez et al. (2015) também verificou que a maltodextrina favoreceu a retenção dos compostos fenólicos em processos de desidratação de frutas. Acima dessa faixa de concentração, o excesso de maltodextrina tornou-se negativo para o processo. Os compostos Flavonoides Totais (Figura 2b) apresentaram comportamento semelhante ao dos fenólicos, com a maltodextrina reduzindo levemente a degradação dos bioativos. Entretanto, a concentração limite foi de 10\%, onde obteve-se um TFC de 3,97 mg rutina/100 g. Em concentrações acima de 10\%, o TFC das amostras se reduziu, atingindo inclusive valores abaixo das amostras sem maltodextrina.

Os teores de ácido cítrico (Figura 2c) também se reduziram após a desidratação, sendo impactados positivamente pela presença da maltodextrina. As variações na concentração do agente carreador pouco influenciaram no processo, mantendo os resultados em uma faixa de $14628 \mathrm{mg}$ ácido cítrico/100 g amostra. Em todos os casos citados acima, os resultados foram inferiores aos obtidos para o material in natura. Na Figura 2d são apresentados os teores de Vitamina $\mathrm{C}$ das amostras após secagem. O ácido ascórbico sempre se mostrou bastante influenciado pelas condições de secagem, uma vez que sua degradação pode estar associada à luz, nível de atividade de água e oxigênio dissolvido, temperatura de processo e até mesmo à presença de metais pesados como cobre e ferro (Sokhansanj e Jayas, 2007). Notou-se que os teores de vitamina $\mathrm{C}$ foram impactados positivamente por concentrações acima de $20 \%$ de maltodextrina e na concentração de $30 \%$ o teor se aproximou do encontrado no material in natura, ou seja, 359,95 mg ácido ascórbico / $100 \mathrm{~g}$ amostra desse composto. Notou-se também que valores baixos de concentrações de maltodextrina promoveram teores de ácido ascórbico até mesmo inferiores do que os observados no material sem o agente.

O efeito das diferentes temperaturas nos teores dos compostos bioativos é apresentado na Figura 3.

Figura 3- Teores de compostos bioativos na secagem de camu-camu- Efeito da temperatura: (a) TPC; (b) TFC; (c) ATT e (d) AA.
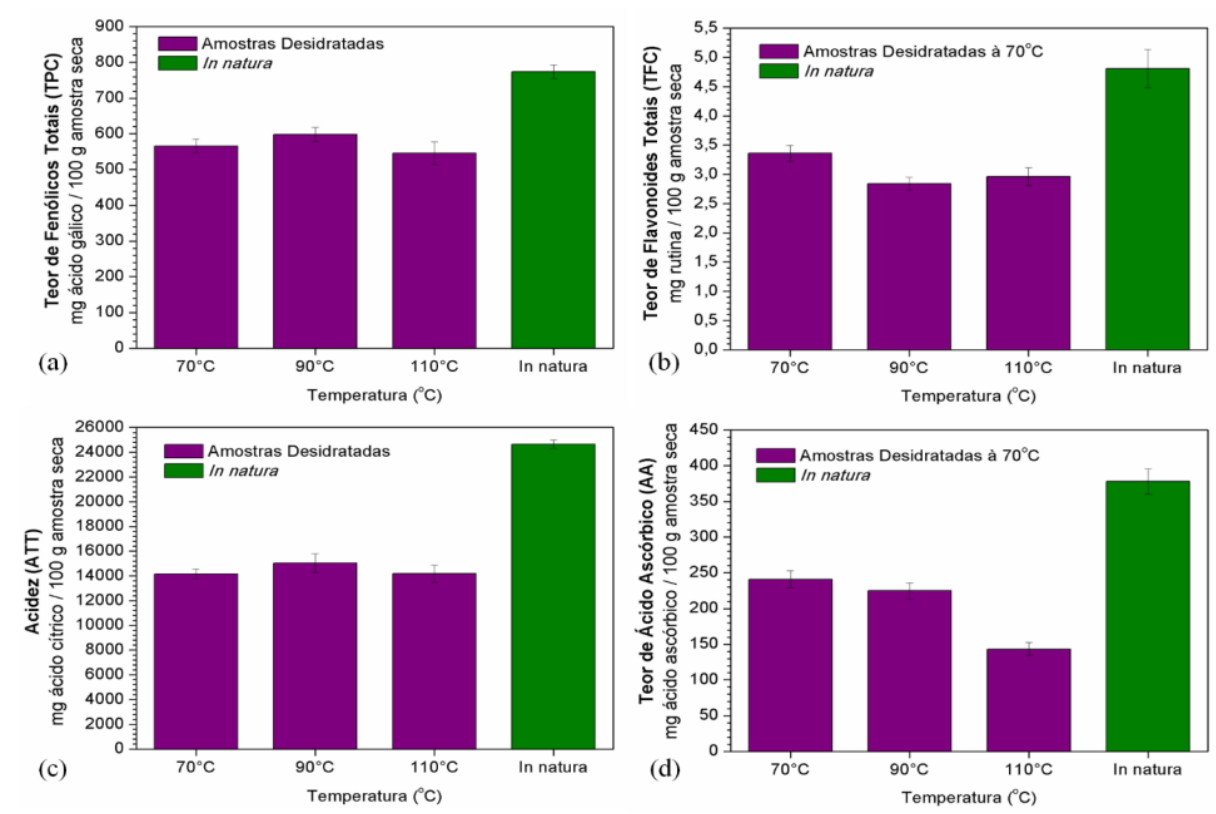


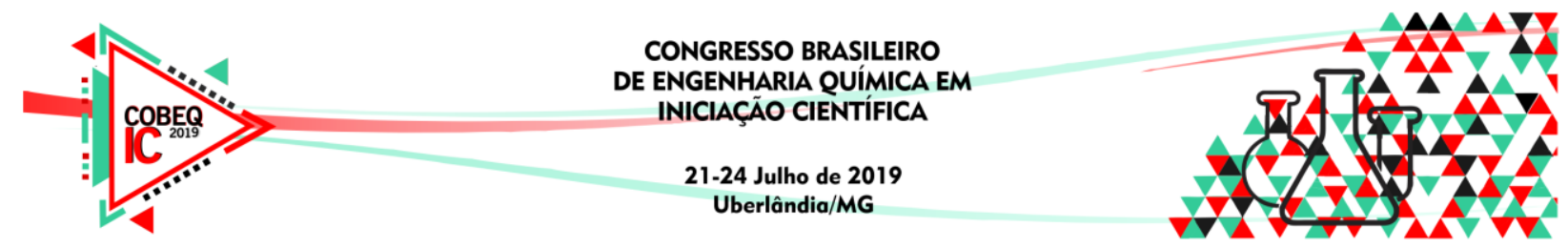

Verificou-se que os teores de Fenólicos Totais (Figura 3a), Flavonoides Totais (Figura 3b) e Acidez (Figura 3c) se mantiveram praticamente estáveis nas diferentes temperaturas avaliadas, o que provavelmente foi favorecido pela presença da maltodextrina nas amostras (15\%), entretanto, os teores apresentaram-se como inferiores ao da polpa in natura. Uma leve degradação foi observada apenas no TFC quando as temperaturas foram elevadas. Observouse também uma termossensibilidade considerável da vitamina $\mathrm{C}$ (Figura 3d), como relatado na literatura. $\mathrm{Na}$ temperatura de $70^{\circ} \mathrm{C}$ foram observados os maiores teores desse bioativo, ainda que tenham valores menores que a polpa in natura. $\mathrm{Na}$ temperatura de $110^{\circ} \mathrm{C}$ verificouse alta degradação do composto, o qual se reduziu a menos da metade do valor da polpa in natura.

Os efeitos das variações no grau de enchimento e rotação nos teores de compostos bioativos podem ser observados na Figura 4.

Figura 4- Teores de compostos bioativos na secagem de camu-camu - Efeito do enchimento e rotação: (a) TPC; (b) TFC; (c) ATT e (d) AA.
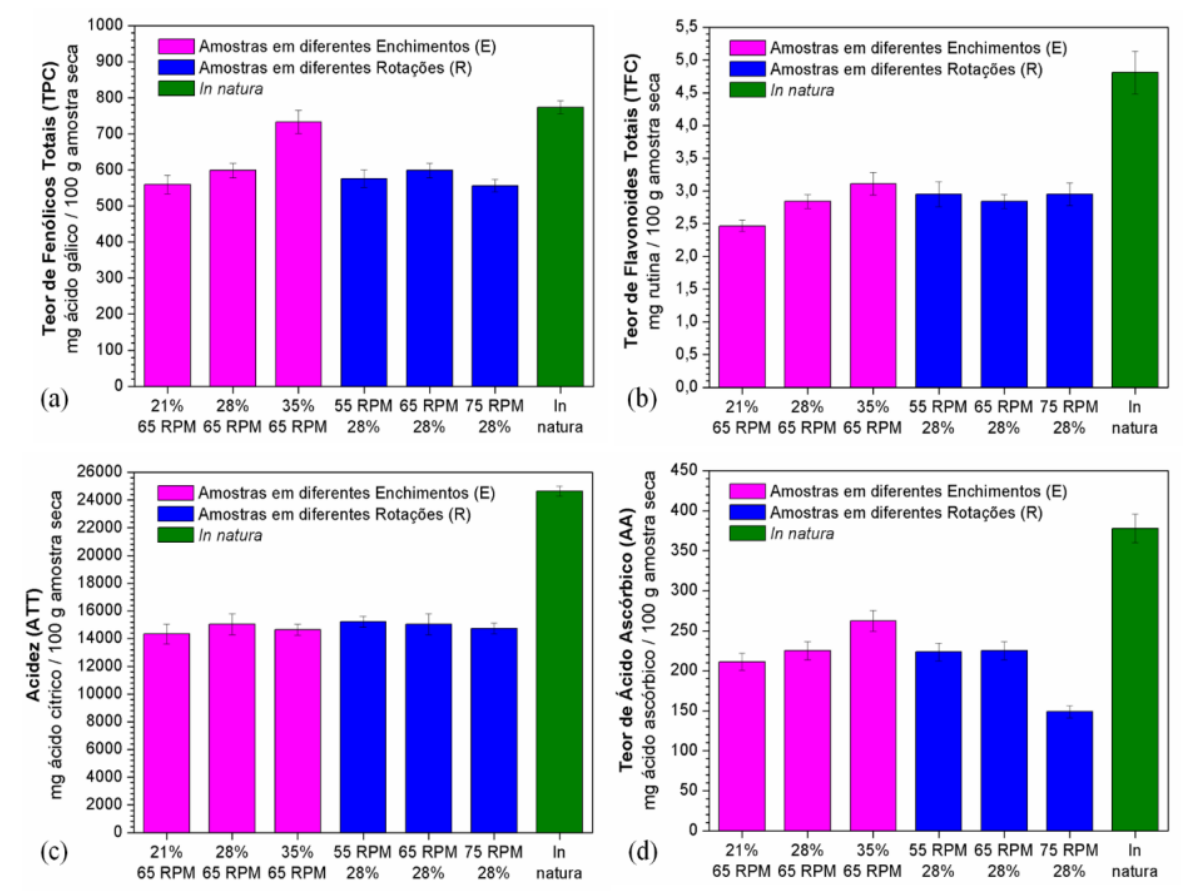

Observou-se que o aumento no grau de enchimento se mostrou favorável aos Teores de Fenólicos Totais (Figura 4a), permitindo obter valores próximos aos do camu-camu in natura quando o Enchimento foi de $35 \%$. Entretanto, para esse composto, as variações na Rotação não surtiram impacto, mantendo os TPCs praticamente intactos, independente da velocidade. Comportamento semelhante ao dos fenólicos foi observado para os Teores de Flavonoides Totais (Figura 4b), com a diferença que o aumento provocado pelo Enchimento foi menos intenso para o TFC que o observado nos fenólicos. Variações na Rotação, mais uma vez, não produziram alterações significativas no teor de flavonoides. A Acidez (Figura 4c), por sua vez, não foi influenciada nem pelo Enchimento ou Rotação adotados, mantendo-se estável em todos as condições experimentais avaliadas. Quanto ao Teor de Ácido Ascórbico (Figura 4d), o mesmo se mostrou positivamente influenciado pelo aumento do Enchimento, mas se 


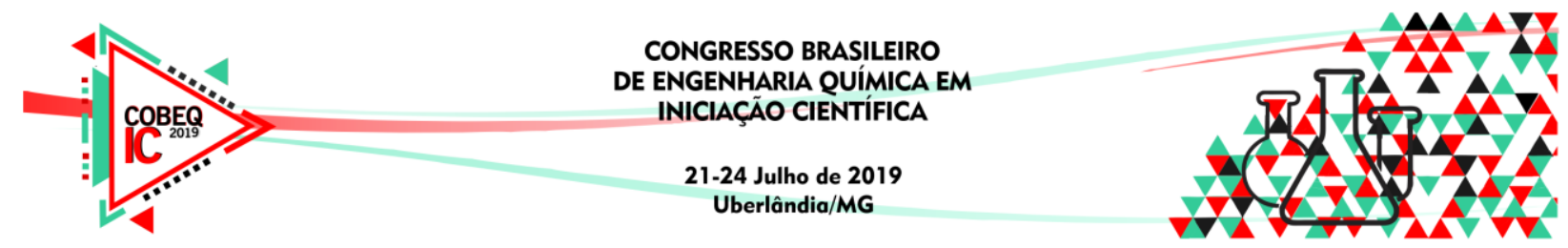

reduziu drasticamente quanto a Rotação foi elevada para 75 RPM, indicando sensibilidade desse composto a essa variável.

\section{CONCLUSÃO}

Observou-se que o procedimento de desidratação do camu-camu no tambor rotatório com recheio de inertes em relação aos compostos bioativos, causou certo impacto nos teores analisados tendo seus valores mantidos próximos ou abaixo dos da polpa in natura sob condições específicas. Apesar disso, ressalta-se que em determinadas condições a maltodextrina atuou como um "protetor térmico" desses compostos, tendo sido observado a manutenção dos teores após a adição da mesma. O único bioativo que se mostrou sensível ao aumento da temperatura foi o ácido ascórbico, cuja termossensibilidade já havia sido relatada. Em relação à variação do fator de enchimento e rotação conclui-se que é melhor utilizar valores intermediários dos mesmos, pois afetam cada bioativo de forma diferente.

\section{REFERÊNCIAS BIBLIOGRÁFICAS}

AOAC, Association of Official Analytical Chemists. Official methods of analysis. Gaithersburg, MD: AOAC, 1995.

FREITAS, L. V. D. Estudo sobre a desidratação de microalgas em secador rotatório. Trabalho de conclusão de curso (Engenharia Química) - Faculdade de Engenharia Química, Universidade Federal de Uberlândia, Uberlândia-MG, 2017

FUJITA, A.; BORGES, K.; CORREIA, R.; FRANCO, B.; GENOVESE, M. Impact of spouted bed drying on bioactive compounds, antimicrobial and antioxidant activities of commercial frozen pulp of camu-camu (Myrciaria dubia Mc. Vaugh). Food Res Int, v. 54, p. 495-500, 2013.

KROKIDA, M. K.; MAROULIS, Z. B.; KREMALIS, C. Process design of rotary dryers for olive cake. Drying Technology, v. 20, n. 4-5, p. 771-788, 2002.

RAMÍREZ, M. J.; GIRALDO, G.I.; ORROGO, C.E. Modeling and stability of polyphenol in spray-dried and freeze-dried fruit encapsulates. Powder Technology, v. 277, p. 89-96, 2015.

RODRIGUES, R. B.; MENEZES, H. C.; CABRAL, L. M. C.; DORNIER, M., RIOS, G. M.; REYNES, M. Evaluation of reverse osmosis and osmotic evaporation to concentrate camu-camu juice (Myrciaria dubia). Journal of Food Engineering, v. 63, p. 97-102, 2004.

SINGLETON, V. L.; ROSSI, J. A. Colorimetry of total phenolics with phosphomolibidicphosphotungistic acid reagents. Am. J. Enol. Viticul., v. 16, p. 144-158, 1965.

SOKHANSANJ, S.; JAYAS, D. S. Drying of Foodstuffs. Em: MUJUMDAR, A. S., Handbook of Industrial Drying, Cap 21, p. 522-546, 3a Edição, CRC Press - Taylor \& Francis Group, Boca Raton-EUA, 2007.

ZHISHEN, J.; MENGCHENG, T.; JIANMING, W. The determination of flavonoid contents in mulberry and their scavenging effects on superoxide radicals. Food Chem., v. 64, p. $555-559,1999$. 